\title{
Alternate Identifier
}

National Cancer Institute

\section{Source}

National Cancer Institute. Alternate Identifier. NCI Thesaurus. Code C90353.

A backup sequence of characters used to identify a study. 